Elsevier Editorial System(tm) for Journal of the Association of Nurses in AIDS Care Manuscript Draft

Manuscript Number: JANAC-D-15-00006

Title: UNDERSTANDING SOCIOCULTURAL FACTORS CONTRIBUTING TO HIV RISK AMONG BOLIVIAN SEX WORKERS.

Article Type: Original Manuscript

Keywords: Bolivia, ethno-nursing, HIV, sexual and reproductive health, transcultural health.

Corresponding Author: Dr. José Granero-Molina, RN. PhD.

Corresponding Author's Institution: ALMERÍA UNIVERSITY

First Author: Olga María López-Entrambasaguas, RN. MSc.

Order of Authors: Olga María López-Entrambasaguas, RN. MSc.; José Granero-Molina, RN. PhD.;

Cayetano Fernández-Sola, RN. PhD.

Abstract: The indigenous Ayoreo population comprises an ethnic group which is very vulnerable to sexually transmitted infections (STIs) and HIV/AIDS. Being a woman, Ayoreo and a sex worker (SW) means belonging to a maximum risk group. Prevention programs for these illnesses are not showing good results among this population. The aim of this study is to explore, describe and understand behavioral and cultural patterns related to sexual and reproductive health among Ayoreo SWs in Bolivia. We designed a qualitative-ethnographic study and data was collected through patient observation and in-depth interviews with the SWs and key informants (KIs). Three fundamental themes emerged from our results: sexual freedom, maternity and control of one's body and the sustaining of risk behaviors. It can be concluded that examining the sexual-reproductive culture in the Ayoreo population in depth provides useful elements for the cultural adaptation and design of policies and prevention programs for STIs and HIV/AIDS. 


\section{TÍTLE}

\section{UNDERSTANDING SOCIOCULTURAL FACTORS CONTRIBUTING TO HIV RISK AMONG BOLIVIAN SEX WORKERS.}

\section{AUTORS}

1. Olga María López Entrambasaguas. RN. MSc. St. George's Healthcare NHS, London, U.K. E-mail: olgaent@ hotmail.com

2. José Granero-Molina. PhD, RN, Senior Lecturer, Department of Nursing, Physiotherapy and Medicine. University of Almería, Spain. Research Associate, Faculty of Health Sciences, Autonomous University of Chile, Temuco, Chile. Phone: 34950214589. E-mail: jgranero@ual.es

3. Cayetano Fernández-Sola. PhD, RN, Senior Lecturer, Department of Nursing, Physiotherapy and Medicine. University of Almería, Spain. Research Associate, Faculty of Health Sciences, Autonomous University of Chile, Temuco, Chile. Phone: 34950214570. E-mail: cfernan@ual.es

\section{AUTOR CORRESPONDENCE}

José Granero-Molina. Department of Nursing, Physiotherapy and Medicine. University of Almería. Health Science Faculty.

Carretera Sacramento S/N ${ }^{\circ}$, La Cañada de San Urbano Almería. Spain.

Phone: 34950214589. E-mail: jgranero@ual.es

\section{DISCLOSURES}

The authors report no real or perceived vested interests that relate to this article that could be construed as a conflict of interest. 


\title{
UNDERSTANDING SOCIOCULTURAL FACTORS CONTRIBUTING TO HIV RISK AMONG BOLIVIAN SEX WORKERS
}

\begin{abstract}
The indigenous Ayoreo population comprises an ethnic group which is very vulnerable to sexually transmitted infections (STIs) and HIV/AIDS. Being a woman, Ayoreo and a sex worker (SW) means belonging to a maximum risk group. Prevention programs for these illnesses are not showing good results among this population. The aim of this study is to explore, describe and understand behavioral and cultural patterns related to sexual and reproductive health among Ayoreo SWs in Bolivia. We designed a qualitative-ethnographic study and data was collected through patient observation and in-depth interviews with the SWs and key informants (KIs). Three fundamental themes emerged from our results: sexual freedom, maternity and control of one's body and the sustaining of risk behaviors. It can be concluded that examining the sexual-reproductive culture in the Ayoreo population in depth provides useful elements for the cultural adaptation and design of policies and prevention programs for STIs and HIV/AIDS.
\end{abstract}

KEY WORDS: Bolivia, ethno-nursing, HIV, sexual and reproductive health, transcultural health. 


\section{INTRODUCTION}

Controlling the epidemic of the human immunodeficiency virus (HIV/AIDS) on a global level continues to be a challenge. With this goal in mind, the United Nations Organization established specific targets to reduce the speed with which HIV/AIDS is spreading, as defined in the Millennium Development Goals (MDGs) for 2015. The control of sexually transmitted infections (STIs) is a basic and fundamental aspect of the global strategy to achieve the MDGs in the areas of maternal and child health and the fight against HIV/AIDS (WHO, 2013a). STIs are a significant public health problem which can increase the risk of HIV acquisition three-fold or more (WHO, 2013b). Improving access to services for the prevention and treatment of STIs constitutes a vital part of the World Health Organization global strategy, focused essentially on ensuring universal access to sexual and reproductive health.

However, despite enormous efforts being made worldwide, HIV infections continue to rise among certain population groups. Reducing the number of new infections requires a global response which would also strengthen social justice, health systems and services in the most vulnerable communities. The UNAIDS strategy goals by 2015 specifically refer to the sexual transmission of HIV being reduced by half, including among young people, men who have sex with men and transmission in the context of sex work (UNAIDS, 2010). However, in spite of international commitments regarding public health, the relationship between STIs-HIV/AIDS/indigenous communities has still not been adopted as a relevant phenomenon in the tackling and containing of the epidemic. As such, policies focused on social groups and ethniccultural minorities at risk (UNAIDS, 2012), such as indigenous communities and sex workers who do not benefit from global advances in sexual and reproductive health resources, are still few and far between.

This is a significant issue in developing countries like Bolivia, an area with many indigenous populations with a high prevalence of risk behaviors in relation to contracting STIs/HIV, such as the Ayoreo community. Until the 1950s, the Ayoreo Indian people, originating from the border between Bolivia and Paraguay, were jungle migrants - gatherers who had developed a primitive agricultural system. Currently, displaced from their original settlements, many live in peripheral neighborhoods in Santa Cruz de la Sierra (Bolivia). The Ayoreo people comprise an ethnic group devastated by extreme poverty, social exclusion, drug addiction and sex work among the younger generations (Roca, 2012). The increase in deaths from HIV in this 
population confirms the ineffectiveness of the prevention programs which have been implemented (López-Entrambasaguas, Fernández-Sola, \& Granero-Molina, 2014). These programs, not adapted to the sociocultural Ayoreo reality, could be overlooking gender inequalities, stigma or discrimination, factors which form key elements in their correct and effective implementation.

It is thus necessary to develop approaches and methods which take this sociocultural dimension into account in order to increase the effectiveness of prevention efforts for the illness (UNAIDS, 2010). Nurses are 'naturals' in ethnography; ethnographic methods offer nurses a broad perspective on people, settings and research topics, allowing them to study health and illness phenomena in context. This methodology could provide information to develop socioculturally-adapted STI/HIV prevention programs focused on indigenous populations such as the Ayoreo community.

\section{BACKGROUND}

The approval of the MDGs in 2000 meant establishing an international commitment in various countries with the aim of improving health in communities. Within this context, given the alarming spread of the HIV epidemic in relation to sexuality, reproduction and the presence of STIs, a global health-sector strategy for responding to HIV/AIDS and STI epidemics was developed. Currently, the 2006-2015 update of the MDGs is in force, focused on ensuring sexual and reproductive health and controlling and preventing STIs, including HIV (WHO, 2006).

STIs are infections which are mainly spread person to person through sexual contact and are caused by diverse organisms. Although on a global level, there has been a progressive increase in curable STIs (syphilis, gonorrhea, chlamydia, trichomoniasis) (WHO, 2013a), STIs are still a major global cause of illness, infertility, long term disability and death. When these infections are not treated, they affect maternal, reproductive and neonatal health, with complications such as genital cancer, infertility, miscarriage, preterm labor, perinatal death and increased risk of contracting HIV developing (WHO, 2013b). The control of STIs is thus fundamental in order to prevent the spread of HIV. Developing improvements in this field could reduce the incidence of HIV infections by up to $40 \%$ among the general population, but above all in high risk groups (WHO, 2006), as is the case with SWs.

Since the start of the HIV/AIDS epidemic more than 30 years ago, unsafe working conditions, barriers to negotiating consistent condom use, lack of access to appropriate 
lubricants, high prevalence of STIs and unequal access to appropriate health services have made the SW population one of the most affected. Social marginalization, criminalization of sex work, violence and drug use in some settings also increases their vulnerability and risk of contagion. Although data varies depending on area, between 2007 and 2011, the global prevalence of HIV in female SWs was 11.8\%, and $6.1 \%$ in Latin America and the Caribbean (WHO, UNPF, UNAIDS, \& NSWP, 2012).

In the Republic of Bolivia, nearly 7000 people had been identified as being affected by HIV by the end of 2011, mainly in the neighborhoods of La Paz, Santa Cruz and Cochabamba. The illness was transmitted sexually in over $90 \%$ of cases, mainly affecting young people and vulnerable groups such as homosexuals, bisexuals, transsexuals and SWs, with a prevalence of $0.6 \%$ (Bolivia Government, 2009). Sentinel studies for the monitoring of HIV and syphilis in women indicate the existence of a concentrated epidemic, in which SWs are the group with the second-highest prevalence (Bolivia Government, 2014). Another related problem is the under-reporting of STIs, even more than HIV, reaching figures of over 50\%. The epidemic has not stopped spreading; by February 2014, the Bolivian Health System had recorded more than 11,421 cases of HIV (Bolivia Government, 2014). However, there is hardly any data regarding indigenous Bolivian populations, and even less in the case of the women. Many indigenous women lack information, being virtually excluded from education related to contraception, skilled assistance at delivery, prevention and treatment of STIs, ways of protecting against domestic violence and safeguarding sexual and reproductive health (Bolivia Government, 2009).

The Ayoreo population is one of 36 indigenous communities living in Bolivia, experiencing extreme poverty, social exclusion and marginalization. Under these conditions, the majority of Ayoreo women resort to sex work from adolescence, continually being exposed to violent situations and the risk of contracting STIs and HIV/AIDS (López-Entrambasaguas, Granero-Molina, \& Fernández-Sola, 2013). Similar to other indigenous communities in Latin America (Cianelli et al., 2008), it is difficult to find up-to-date and specific health indicators for the Ayoreo community, as the majority do not go to health centers unless they are seriously ill or dying. No specific data is available regarding HIV and the Ayoreo population. However, empirical information and data provided by non-governmental organizations (NGOs) show an increase in cases of HIV and deaths due to AIDS (Roca, 2012). Recognizing the risks that Ayoreo people have in Bolivia, various associations have developed activities 
focused on identifying the health needs of the Ayoreo community regarding HIV, including Apoyo Para el Campesino-Indlgena del Oriente Boliviano (Support for Indigenous People in Eastern Bolivia), Centro Departamental de Vigilancia y Referencia de ETS/VIH/SIDA (Central Department for the Monitoring and Reference of STIs/HIV/AIDS), Eриа Kuñatai Foundation, Ibis-Hivos Association and NGOs such as Enfermeras para el Mundo (Nurses for the world). The work carried out by such organizations is revealing the importance of social immersion and the understanding of the Ayoreo community as a step prior to any health intervention in these communities (Roca, 2012).

Ethnography is a qualitative research methodology which has proved fitting for the study of health problems in little-explored areas, allowing for a cultural interpretation of the data (Holloway \& Todres, 2006). If we intend to better understand cultural and sexual and reproductive health practices among Ayoreo SWs, the difficulty in accessing the field leads us to cast aside conventional ethnography, thus choosing to employ a focused ethnography, allowing us to obtain and assess information on a specific topic or experience in a determined research area. Our study is based on Madeleine Leininger's Culture and Care Theory (Leininger, 2002), the aim of which is to provide safe, culturally-adapted care, taking world view, social structures and environmental context into account (Leininger, 2006). This vision coincides with the UNAIDS recommendations regarding factors to consider in the development of HIV/AIDS prevention programs.

\section{Aims}

The aim of this study is to explore, describe and understand the cultural and behavioral patterns associated with sexual and reproductive health among Ayoreo SWs, as well as the prevention of STIs and HIV/AIDS.

\section{METHODS}

\section{The research approach}

Using a naturalist paradigm and a phenomenological perspective, we designed a mini-ethnographic study based on the Theory of Cultural Care: Diversity and Universality (Leininger, 2002). Ethno-nursing is a research method focused on the way of understanding and experiencing the lives of its participants (Leininger, 2006). We developed a mini ethnography — a small-scale ethnography focused on a specific area of 
investigation, which can be adapted to the objective and the temporal limitations of the study (Wolf, 2012). If ethnography allows us to observe specific social realities, critical ethnography is necessary for health promotion, as it is focused on changing the realities of marginalized, oppressed and minority groups, as is the case with SWs.

\section{Data collection}

Data collection took place between November and December, 2011 in Santa Cruz de la Sierra, Bolivia, through participant observation and individual interviews. The study sample consisted of 12 participants - 8 key informants (KI) and 4 SWs. The KI sample was determined by data saturation. The number of SWs was less than originally planned due to the assassination of a SW in the neighborhood where data collection was taking place. The incident was completely unrelated to our research, however we had to leave the field and stop interviews because of the lack of safety in the area. The field work included visiting health centers, workplaces of the KIs, neighborhoods inhabited by the Ayoreo community and streets where the SWs work as prostitutes. Observation was carried out for 6 hours a day; field notes (FN) were taken, including dates, places, interactions, environmental conditions and activities, as well as the personal reflections, perceptions and expressions of the participants. The interviews with the KIs lasted between 45 and 60 minutes and those with the SWs from 15 to 30 minutes.

\section{Data analysis}

Analysis was guided by the four stages of ethnonursing described by $\mathrm{M}$. Leininger (Leininger, 2006). First stage: the researcher compiled the data collected in the FN and the recorded interviews, which were then transcribed and listened to again to ensure the integrity of the data within a contextual meaning. Second stage: the transcriptions were read and codes were assigned to specific sections describing the meaning of data in the interviews. The FN were also examined, looking for similarities, differences and meanings. Third stage: the researcher studied the data, grouping codes into conceptual categories, paying attention to non-verbal behaviors and contextual elements which could affect meaning. Fourth stage: an inductive analysis was carried out (Hammersley \& Atkinson, 2007), allowing for the extraction/emergence of themes, sub-themes and units of meaning. As a criterion of scientific validity of the study results, and to ensure an in-depth understanding of the studied phenomenon, a 
triangulation process was carried out between three researchers. The qualitative analysis was carried out with help from ATLAS.ti 7 software.

\section{Ethical issues}

The study was approved by the ethics research committee of the University of Almeria (Spain). Free and informed consent was obtained before the interviews took place and once the nature and purpose of the study had been explained. Confidentiality and anonymity were ensured as well as the possibility of refusing to participate or answer the questions. All informants were provided with a code (SW or KI) to protect their identity. All work described has been carried out in accordance with The Code of Ethics of the World Medical Association (Declaration of Helsinki).

\section{Rigor and limitations:}

Credibility is present in our analysis since its results show the situation studied, consistency since the information has been triangulated, reflection because now there is an opinion trend in Santa Cruz nursing, and relevance because objectives are achieved as we improve our understanding of the situation.

\section{RESULTS}

The findings are presented in three sections, reflecting the major themes identified by the researchers: sexual freedom, maternity and control of one's own body, and sustaining risk behaviors. The subthemes and units of meaning of each theme can be seen in table 1 (Table 1).

Insert here Table 1.

\section{Theme 1. Sexual freedom}

This theme refers to the freedom women have in relation to sexuality. The culturally-accepted practices in the jungle (before incorporation into western culture) allowed young Ayoreo women to experiment with various men before establishing a stable relationship with one. They also had a lot of influence in the making of decisions regarding sexual relationships. This theme consists of two subthemes:

\section{Subtheme 1. Sought after promiscuity and sexual experimentation}


Sexual experimentation, promiscuity and the absence of taboos when discussing sexuality in adolescence are defined as elements which are characteristic of the Ayoreo culture. Sexuality is also "talked about" - groups of young people meet up, talk openly about sexuality, exchange information and discuss the topic with other people. Unlike other populations, Ayoreo marriages were based on romantic love, and it was common for women to initiate/have various relationships before choosing one man. After moving to urban areas, this cultural idea of sexuality has been kept, and it is normal for them to take the initiative in sexual advances with men:

“(...) today Informant No. 2 has also confirmed that in the Ayoreo population, it is the women who propose sex to the men and promiscuity and experimentation with various partners during adolescence is normal, until they find the person to marry. But then, things change, as they have to be faithful (...)." (FN-3).

This situation may have an influence when it comes to how the Ayoreo people understand/accept promiscuity. Supported by this cultural idea and encouraged by their own society, it is the women who, after having their first period, initiate sexual relationships with various men. When this practice is transferred to city life, together with the act of receiving material or economic compensation, they become SWs - a "culturally-accepted" activity which constitutes the basic economic support/upkeep of many Ayoreo families

“(...) I've also heard a lot that if the woman has been with a lot of men-more sexual relationships - she's well-regarded, unlike our idea, right?”(KI-3).

\section{Subtheme 2. Social and sexual empowerment}

This is based on a native "empowerment" which gives Ayoreo women freedom in relation to sexual relationships. When a woman from a powerful family married an orphaned man, or one from a small family, she had the power and ability to make decisions. However, an orphaned woman, or one without family, was always weaker than a man in the same circumstances; if the husband was the one who came from a powerful family, she could hardly say anything. After leaving the jungle and moving to the outskirts of the cities, this has changed. Similar to the rest of Bolivian society, the woman finds herself in a position of social disadvantage and suffers gender inequality. Being a woman and Ayoreo increases marginalization, violence and abuse; they are forced into sex work, with the consequent risk of contracting and transmitting STIs and 
HIV. Although Ayoreo SWs deny it, the informants doubt their ability to impose decisions.

"Do you use a condom?" "Yes, always." "And if the men don't want to, what happens?" "I don't want to do it, I don't do it." (SW-1)

“(...) She is in charge. Yes, well at least that's what I know. They impose what they want and refuse to do what they don't want. For example, do you want to have anal sex? I don't want to, I don't do it, I don't have it, I'm not going to have it and if you insist, I'll hit you, I'll throw a stone at you, I'll burn you, I'll go and burn your face (laughs). (...) It's a very combative spirit but now, there's that, now the men who manage to do it in the moment while already in the sexual act, manage to impose all their... whatever they want. We know of countless episodes of violence against the women, attempted rapes and all kinds of abuse (...). $”(K I-2)$

\section{Theme 2. Maternity-Control of one's own body}

This category refers to the control that Ayoreo SWs have over their own body, above all in relation to topics regarding pregnancy and maternity. Two subthemes emerged in the fieldwork:

\section{Subtheme 1. Interest in contraceptive methods}

Although Ayoreo sex workers are virtually excluded from any type of health education, they show interest in contraceptive methods and are concerned about avoiding unwanted pregnancies. Contributing to this could also be the fact that pregnancy and bringing up a child is culturally associated with long periods of lactation, during which the woman would have to stop sexual activity. For SWs, this would act as an obstacle to carrying out their activity and as such, a loss of economic resources for themselves and their families. For this reason, it is not surprising that there is more concern regarding pregnancy than STIs. In line with the lack of a health structure and custom of going to family planning or health care services, they prefer convenient methods which require few visits to social or health centers, as a KI and a SW confirmed:

“(...) Let's say that women see a need for contraceptives. They're very scared or they want to stop themselves from getting pregnant." (KI-4) 
"Yes, yes. And they also prefer 3-month injections or longer acting ones. A lot use the coil. Yes, they are concerned about that (...)." (KI-1)

“They give me an injection you see, so I don't get pregnant." (SW-2)

"I don't know what that family planning is. We don't have it. I don't know..." $(S W-4)$

\section{Subtheme 2. Maternity linked to marriage}

In the Ayoreo population, the acceptance of children is determined by the existence or not of a father figure. More than a wanted or unwanted child, they speak about a child within a stable relationship (marriage) or a fatherless child. An unwanted child is traditionally one who does not have a father. Since the time they were living in the jungle, having children without a father has been a source of social stigma and a child without a father was directly buried or abandoned.

“(...) people clearly distinguish, no so much between a wanted or unwanted pregnancy, but between a pregnancy in a relationship or without a father. Having a child without a father has always been a strong stigma. (...) so a fatherless child was buried straightaway." (KI-1)

“(...) before, they didn't have abortions. They waited 'til the child was born and then buried it (...) Maybe not last year but maybe 5 or 10 years ago.” (KI-4)

Today, contact with western culture has tempered this custom, but the cultural background of rejecting a fatherless child remains. If traditionally an unwanted child was abandoned, killed or left to die, new measures such as abortion or adoption complement culturally-accepted solutions in today's society. From the testimonies analyzed, it can be deduced that these new measures have not eliminated the traditional practice of abandonment:

"There are still some that do it. Or they even leave them to die, I mean, they leave the children to die who are very weak." (KI-4)

“(...) Yes, we had a case about 2 years ago. (...) In the end, she abandoned the baby. (...) That girl is pregnant at the moment." (KI-3)

“(...) Giving the baby away is related to the fact that it is unwanted. If the child is wanted, loved, it's going to stay, if not, it's going to be given away, it's going to be given up for adoption to family, to someone (...). But if it is an unloved 
child, it's not given milk, it's not recognized as a son or daughter and is abandoned (...)." (KI-2)

Abortion remains hidden; it is not a practice which is requested and is not something which the women turn to the health services for. Cases of abortion are known about because the women go to health services but due to complications arising from it.

"Well, indirectly we know of cases existing [of induced abortion], they've admitted it and there have also been cases of complications because of it (...)." $(K I-1)$

"Yes, there are abortions. There are pregnancies at an early age and like anywhere, there are abortions. The thing is we don't know about the conditions or where." (KI-2)

\section{Theme 3. Sustaining risk behaviors}

This theme refers to the fact that the SWs sustain high health risk behaviors, and specifically regarding STIs, as confirmed by the informants. This theme includes two fundamental subthemes:

\section{Subtheme 1. Cultural determinants}

The concept of health or family planning does not exist in the Ayoreo community, nor does a culture of prevention. The SWs go to the health center when they see the severity of their symptoms, but never to request preventive measures, as various informants reveal:

"I can say for definite that none of the women go to a health registration - none of them have a periodic, regular check-up to see the condition of their health." $(K I-8)$

"And how did you know you had an infection [STI]?" "Because they came here to the community you see and the doctor told me." (SW-1)

This practice may lead to delays in care, until complications or the progression of the illness make the patient realize the gravity of the situation:

“(...) it depends on how they see the symptom as to whether they think it's serious or not (...). What I've seen in many cases is that people come to the health center when they're already ill. It happens with everything, even with 
diabetes diagnoses, when they faint or are going blind. So it's not like they had a routine check-up or anything, but that they fell, they were taken to hospital and they discovered that they were diabetic." (KI-5)

“(...) cases of death due to aggressive STIs where they've ended up having worms coming out of people... I've gone with somebody to a health center and they told me that the girl had at least four infections, that she had pus coming out of her everywhere, so it's terrible." (KI-7)

In some cases, the Ayoreo people turn to the use of tradition medicine, and combine it with western medicine, which ends up creating confusion when attributing the success to the therapies:

“(...) there are people who have recovered after a health-illness episode after going to health center and taking their traditional medicine, or witchcraft and everything, and in the end, they're confused because they don't know who cured them." (KI-6)

Pregnancy is not seen as an obstacle to continue sex work, which implies a potential risk of the vertical transmission of STIs/HIV:

"In some cases there are mothers who continue working as prostitutes. In other cases, there are young, pregnant women prostituting themselves - maybe 4 months pregnant, 5 or 6 but they keep working." (KI-5)

\section{Subtheme 2. Social determinants}

Elements such as the social invisibility of the studied population, due to both being Ayoreo and SWs contribute to the increased vulnerability in relation to STIs. Another of these elements which emerged in data analysis was drug addiction, which seemed to be quite common among the studied group. The participants stated that the SWs associate prostitution with the consumption of easily-accessible drugs at a low economic cost, as two informants expressed:

“(...) prostitution also comes linked to all of the vices: inhalants, 'clefa', that shoe glue, since that's the cheapest and the most accessible. But there's also cigarettes, marijuana, cocaine...” (KI-2) 
“We've worked with 10-11 young girls (...) They all take drugs (...). They stop with their little jar of clefa, a substance used to repair shoes and glue wood. It's a chemical - they inhale it and leave with that little jar, hiding it." (KI-3)

Among the social determinants can be found those related to the knowledge and attitude they have regarding their sexual and reproductive health rights. In this sense, the SWs were not aware of their rights due to engaging in sex work, the health services they could benefit from or the legislation related to STIs/HIV/AIDS:

"As I said, it's the majority, except for a few which are exceptional cases, you know? The ones who are interested, who get their card, who look after themselves and for some reason or another, who are more interested or have access to it (...)." (KI-1)

"Are you registered as a sex worker "Y"? Do you have the card?" "No, I still don't have it" "And do you know - if you have the card - do you know what you have to do?" (silence) "Do you know your rights? Because if you have the card, they give you an HIV test every six months and you'd have to have check-ups as well. Did you know that?" "No". (SW-4)

"And if you get ill, do you know where you have to go to so that they can make you better?" "No, but they told me that if you want to have a check-up, you have to go to the hospital on October $10^{\text {th }}$, they told me. (SW-3)

\section{DISCUSSION}

The aim of this study was to explore, describe and understand the cultural and behavioral patterns associated with sexual and reproductive health among Ayoreo SWs, together with the prevention of STIs/HIV. The adoption of an ethnographic approach allowed us to better understand the cultural dimension of the study phenomenon from the emic point of view (Leininger, 2006), which is of use when implementing programs and measured aimed at changing the social reality of marginalized and minority groups (López-Entrambasaguas, Fernández-Sola \&, Granero-Molina, 2014).

The start of sexual discovery and sexual relationships happens at an early age in Ayoreo women; knowledge seems to be gained from the exchanging of information among peer groups. Various testimonies confirm the fact that at this stage of life, the young women express their sexuality freely and with different partners, until finding the person that they will decide to have a stable and permanent relationship with in married 
life. Ayoreo women take on an active role (Roca, 2012) - they take sexual initiatives with the aim of experimenting and seeking pleasure until they establish a stable relationship and in doing so, the diversity of sexual partners ends. Furthermore, the woman may adopt a passive role, where the power of decision making depends on the family's social status; if the girl is an orphan, she will scarcely be considered and is even discriminated against in her community, possibly being forced into sex work (López-Entrambasaguas, Fernández-Sola \&, Granero-Molina, 2014).

Coercion may also be a reason why they engage in prostitution and sex work; the difference in power between family groups is a significant determinant in an Ayoreo woman's freedom to make decisions (Roca, 2012). However, this cultural and natural "female promiscuity" which was only among Ayoreo people when they lived in the forest before 1950, has turned into exchanging sexual favors for money with nonindigenous men (cojñone, in the Zamuco language). Now, the motive behind Ayoreo women prostituting themselves is not only sexual experimentation but survival, as they live in conditions of extreme poverty and it is their livelihood (López-Entrambasaguas, Fernández-Sola \&, Granero-Molina, 2013).

The way in which an Ayoreo woman understands maternity and control constitutes an essential element to consider prior to planning activities for the prevention of STIs/AIDS. Maternity is important for adult women with a stable partner, a positive attribute of being a "good mother". Three of the four women interviewed were mothers and the fourth expressed a desire to be one when she finds a husband. A woman without children has less status in the community (Roca, 2012), and therefore, the stable father figure plays a basic social role. Being a single mother is a stigma, both for the woman and the child, and as such, the women are very careful to protect themselves from unwanted pregnancy. Social instability continues to be the primary cause of abortion among indigenous women. Unlike when they lived in the forest, it seems that now, they do not resort to infanticide, but they do still have clandestine abortions, abandon unwanted babies, do not feed them or leave them to die.

In relation to avoiding unwanted pregnancies, it is common for Ayoreo women to use "western" contraception, unlike other indigenous groups which have been studied (Ishida et al., 2012; Wurtz, 2012). They are mainly interested in the non-barrier modern contraceptive methods, specifically the long-acting injections. The use of herbs and sarode (traditional medicine) is another preventive method (Roca, 2012), as well as withdrawing before ejaculation. This latter practice leads us to understand that 
consistent condom use is not established within the population studied (LópezEntrambasaguas, Fernández-Sola \&, Granero-Molina, 2013), an issue examined in other research carried out with different aboriginal groups (Mill et al., 2011). Furthermore, it has been shown that women who use other contraceptive methods are less likely to use condoms (Yam et al., 2013). The greater vulnerability to STIs and the consequences these women face are applicable not only to their partners and clients but also to their possible newborn babies. We not only found testimonies that confirmed that some girls continue engaging in prostitution when they are pregnant, but that furthermore, they do not go to health centers to seek help and treatment until the illnesses are extremely evident.

Our informants indicate that the SWs often resort to their traditional medicine and only when they are very ill do they resort to the western health system. Previous studies of Ayoreo women have already revealed this avoiding of health services, explained in part by the poor relationships and discrimination they suffer from the nonindigenous Bolivian population, including health professionals (López-Entrambasaguas, Fernández-Sola \&, Granero-Molina, 2013). Standing out among the motives influencing indigenous women's decision to seek care is access to culturally appropriate, safe and secure health care services, and the feeling of being valued and treated with dignity. Cultural and language barriers have also been shown to be prominent deterrents for indigenous community members in seeking care (Ishida et al., 2012). In the case of the SWs, the inconvenient location of the clinics, judgmental attitudes of health care providers and lack of information about available services have also been reported (Phrasisombath et al., 2012).

Although other motives are unknown, another aspect to consider is that the SWs studied frequently resort to drug addiction, a risk behavior which makes them more vulnerable to HIV and other STIs. Other studies have shown that drug-using sex workers were about half as likely to use condoms as those who did not use drugs (MAP, 2005). Strong relationships between sex work and drug abuse have been found, with an increased risk of contracting HIV and other STIs (Yao et al., 2012), and even with being victims of sexual and physical abuse (Ulibarri, Strathdee \&, Patterson, 2010). There is a need to put culturally-appropriate interventions in place, which take advantage of the existing health-related resources and infrastructures. Programs such as "Mano a Mano para trabajadores de Salud', (Hand in Hand for Health Workers) can increase health workers' knowledge in the prevention of violence, STIs and HIV (Norr et al., 2012). 


\section{Limitations}

The limitations of this study are determined by two fundamental factors. The first: the sample size of the SWs. Due to the lack of safety in the area after the murder of a SW, the main researcher followed advice from the local authorities and had to cancel visits to the neighborhood, therefore interrupting the fieldwork. Interviews with new SWs could show different results; however, the KIs displayed good knowledge of the studied community, having worked with it for many years. The second: the study context itself. This article forms part of a wider research program carried out with female Ayoreo SWs, studying their beliefs and attitudes regarding HIV/AIDS and the success/failure of existing prevention programs. A general overview would have brought greater richness to the study but would have been detrimental to its profundity.

\section{CONCLUSIONS AND IMPLICATIONS FOR PRACTICE}

In this study, we have described and analyzed important cultural and behavioral characteristics related to sexual and reproductive health and the risk of contracting STIs/HIV among a group of indigenous Bolivian women, a group which has not been greatly studied. Sex work constitutes part of their lives from puberty to when they find a stable partner and have a family. They have significant sexual freedom and want to have control in terms of motherhood and avoiding unwanted pregnancies and as such, resort to clandestine abortions or abandonment of the newborn baby if they do fall pregnant unintentionally. They delay or completely avoid going to medical centers when they have problems with their health and show a lack of knowledge and/or interest in terms of taking care of their health from a western point of view, and often turn to drug use.

All of the patterns we are describing indicate that this population group is heavily exposed to the risk of contracting STIs/HIV, with the additional aggravating factors of poverty, violence and social marginalization surrounding them. These findings have implications for the design and conduct of STIs/HIV intervention, care and treatment programs for Ayoreo sex workers. As different studies have shown, successful measures to prevent STIs in SWs include community mobilization, group support and community-based organizations (Reza-Paul et al., 2008; Lippman et al., 2010; Pelcastre-Villafuente et al., 2014). Also, and according to Wurtz (2012), several studies have demonstrated that a community-based participatory research methodology may be an appropriate and effective approach to health research with and within indigenous populations. Health professionals could design interventions, provide 
women with additional resources to deal with violent situations and actively protect themselves from contracting STIs/HIV/AIDS (Choudhury, Anglade, \& Park, (2013).

\section{Acknowledgments}

The authors would like to express their gratitude to the young Ayoreo women who participated in the study, to the informants who took part in the interviews and who made it possible for the main researcher to access the area, and finally to the NGO Enfermeras para el Mundo (Nurses for the World). 


\section{REFERENCES}

Bolivia Government. (2009). Plan Estratégico Nacional de Salud Sexual y Reproductiva 2009-2015. [National Sexual and Reproductive Health Strategy 20092015]. Retrieved from http://www.ine.gob.bo/indicadoresddhh/archivos/salud/nal/PLAN\%20ESTRATEGI CO\%20NACIONAL\%20DE\%20SALUD\%20SEXUAL\%20Y\%20REPRODUCTI VA.pdf

Bolivia Government. (2014). Informe Nacional de progresos en la respuesta al VIH/SIDA, 2014. Seguimiento a la Declaración Política sobre el VIH/SIDA 2011. [Country Progress Report On The Hiv Response 2014. Monitoring the Political Declaration on HIV / AIDS 2011]. Retrieved from http://www.unaids.org/sites/default/files/country/documents//BOL_narrative_report _2014.pdf

Choudhury, S.M., Anglade, D. \& Park, K. (2013). From violence to sex work: agency, escaping violence, and HIV risk among establishment-based femalesSex workers in Tijuana, Mexico. Journal of the Association of Nurses In Aids Care, 24(4), 368-382.

Cianelli, R., Ferrer, L., Cabieses, B, Araya, A., Matsumoto, C., \& Miner, S. (2008). HIV Issues and Mapuches in Chile. Journal of the Association of Nurses in Aids Care, 19(3), 235-241.

Hammersley, M., \& Atkinson, P. (2007). Ethnography: Principles in practice (3rd ed.). London: Routledge.

Holloway, I., \& Todres, L. (2006). Ethnography. In: K. Gerrish \& A. Lacey (Eds.). The Research Process in Nursing. Oxford: Blackwell Publishing.

Ishida, K., Stupp, P., Turcios-Ruiz, R., William, D.B., \& Espinoza, E. (2012). Ethnic inequality in Guatemalan women'a use of modern reproductive health care. International Perspectives on Sexual and Reproductive Health, 38(2), 99-108.

Joint United Nations Programme on HIV/AIDS UNAIDS. (2010). 2011-2015 Strategy. $\begin{array}{llll}\text { Getting } & \text { to } & \text { Rero. } & \text { from }\end{array}$ http://www.unaids.org/sites/default/files/en/media/unaids/contentassets/documents/u naidspublication/2010/JC2034_UNAIDS_Strategy_en.pdf

Joint United Nations Programme on HIV/AIDS (UNAIDS). (2012). Unidos contra el SIDA: hacia la consecución de las metas establecidas en la Declaración política de 2011. [Unite against AIDS: towards achieving the goals set in the 2011 Political 
http://www.unaids.org/sites/default/files/en/media/unaids/contentassets/documents/d ocument/2012/20120402_UNGA_A-66-757_es.pdf

Leininger, M. (2002). Essential transcultural nursing care concepts, principles, examples, and policy statements. In: M. Leininger \& M. R. McFarland (Eds.). Transcultural nursing: Concepts, theories, research, and practice (3rd ed.). New York: McGraw-Hill.

Leininger, M. (2006). Ethnonursing: A research method with enablers to study the theory of culture care. In: M. Leininger \& M. R. McFarland (Eds.).Culture care diversity and universality: A worldwide nursing theory (2nd ed.). London, Jones \& Bartlett.

Lippman, S.A., Donini, A., Díaz, J., Chinaglia, M., Reingold, A., \& Kerrigan, D. (2010). Social-environmental factors and protective sexual behaviour among sex workers: the Encontros intervention in Brazil. American Journal of Public Health, 100(S1), S216-S223.

López-Entrambasaguas, O. M., Granero-Molina, J., \& Fernández-Sola, C. (2013). An ethnographic study of HIV/AIDS among Ayoreo sex workers: Cultural factors and risk perception. Journal of Clinical Nursing, 22, 3337-3348.

López-Entrambasaguas, O. M., Fernández-Sola, C., \& Granero-Molina, J. (2014). Perception of HIV Prevention Programas among Ayoreo Sex Worker in Bolivia. Journal of Transcultural Nursing. 1-8. Retrieved from http://0tcn.sagepub.com.almirez.ual.es/content/early/2014/05/20/1043659614526254.full.pd f+html

Monitoring the AIDS Pandemic (MAP) Network. (2005). Sex work and HIV/AIDS in Asia. MAP 2005. Report Retrieved from http://www.aidsdatahub.org/sites/default/files/documents/MAP_Report_2005_Sex_ Work_and_HIVAIDS_in_Asia.pdf

Mill, J.E., Wong, T., Archibald, C., Sommerfeldt, S., Worthington, C., Jackson, R., Prentice, T., \& Myers, T. (2011). "AIDS is something scary": Canadian aboriginal youth and HIV testing. Pimatisiwin: A Journal of Aboriginal and Indigenous Community Health, 9 (2), 277-299.

Norr, K.F., Ferrer, L., Cianelli, R., Crittenden, K.S., Irarrazabal, L., Cabieses, B., Araya, A., \& Bernales, M. (2012). Peer group intervention for HIV prevention among 
health workers in Chile. Journal of the Association of Nurses In Aids Care, 23(1), 73-86.

Pelcastre-Villafuerte, B., Ruiz, M., Meneses, S., Amaya, C., Márquez, M., Taboada, A., et al. (2014). Community-based health care for indigenous women in Mexico: a qualitative evaluation. International Journal for Equity in Health, 13(2), 1-9.

Phrasisombath, K., Thomsen, S., Sychareun, V., \& Faxelid, E. (2012). Care seeking behaviour and barriers to accessing services for sexually transmitted infections among female sex workers in Laos: a cross-sectional study. BMC Health Services Research, 12:37. Retrieved from http://www.biomedcentral.com/1472-6963/12/37

Reza-Paul, S., Beattie T., Syed, H.U., Venukumar, K.T., Venugopal, M.S., Fathima, M.P., et al. (2008). Declines in risk behaviour and sexually transmitted infection prevalence following a community-led HIV preventive intervention among female sex workers in Mysore, India. AIDS, 22(Suppl 5), S91-100.

Roca, I. (2012). Aproximaciones a la situación del derecho a la salud del pueblo Ayoreode en Bolivia [Ideas on the situation of the Ayoreo population's right to health in Bolivia]. Santa Cruz de la Sierra, Bolivia: Apoyo al Campesino-indígena del Oriente Boliviano (APCOB), Central Ayorea Nativa del Oriente Boliviano (CANOB).

Ulibarri, M.D., Strathdee, S.A., \& Patterson, T.L. (2010). Sexual and drug use behaviors Associated with HIV and other sexually transmitted infections among female sex workers in the Mexico-U.S. Border Region. Current Opinion in Psychiatry, 23(3), 215-220.

World Health Organization. (WHO). (2006). Global strategy for the prevention and control of sexually transmitted infections: 2006-2015. Retrieved from http://whqlibdoc.who.int/publications/2007/9789241563475_eng.pdf?ua=1.

World Health Organization (WHO). (2013a). Baseline report on global sexually transmitted infection surveillance 2012. Retrieved from http://apps.who.int/iris/bitstream/10665/85376/1/9789241505895_eng.pdf

World Health Organization (WHO). (2013b). Sexually transmitted infections (STIs). The importance of a renewed commitments to STI prevention and control in achieving global sexual and reproductive health. Retrieved from http://apps.who.int/iris/bitstream/10665/82207/1/WHO_RHR_13.02_eng.pdf?ua=1 
World Health Organization (WHO), United Nations Population Fund (UNPF), Joint United Nations Programme on HIV/AIDS (UNAIDS), \& Network of Sex Work Projects (NSWP). (2012). Prevention and treatment of HIV and others sexually transmitted infections for sex workers in low- and middle-income countries. Recommendations for a public health approach. Retrieved from http://apps.who.int/iris/bitstream/10665/77745/1/9789241504744_eng.pdf

Wolf, Z. R. (2012). Ethnography: The method. In: P. Munhall (Ed.). Nursing research: a qualitative perspective (5th ed.). London: Jones \& Barlett Learning.

Wurtz, H. (2012). Indigenous women of Latin America: unintended pregnancy, unsafe abortion, and reproductive health outcomes. Pimatisiwin: A Journal of Aboriginal and Indigenous Community Health, 10(3), 271-282.

Yam, E.A., Tinajeros, F., Revollo, R., Richmond, K., Kerrigan, D.L., \& García, S.G. (2013).Contraception and condom use among bolivian female sex workers: relationship-specific associations between disease prevention and family planning behaviors. Health Care for Women International, 34(3-4), 249-262.

Yao, Y., Yang, F., Chu, J., Siame, G., Lim, H.J., Jin, X., Ding, G., Sun, Y., Wang, G., Yu, Y., \& Wang, N. (2012). Associations between drug use and risk behaviours for HIV and sexually transmitted infections among female sex workers in Yunnan, China. International Journal of STD \& AIDS, 23(10), 698-703. 


\section{KEY CONSIDERATIONS}

- After moving from jungle life to a western way of life, the indigenous Ayoreo population has maintained cultural traditions which increase the risk of contracting/transmitting STIs and HIV/AIDS.

- Sex work has become a way of financial support for Ayoreo families, who encourage their daughters to practice prostitution.

- Being a woman, indigenous and a SW significantly increases the risk of contracting/transmitting STIs and HIV/AIDS.

- Improving understanding of cultural and behavioral patterns associated with sexual and reproductive health among Ayoreo SWs could help to better prevent STIs/HIV.

- The success of any preventative intervention for STIs/HIV/AIDS in the Ayoreo population depends on institutions, NGO administrators and health workers taking these sociocultural aspects into account. 
Table 1. Themes, subthemes and units of meaning.

\begin{tabular}{|l|l|l|}
\hline Theme & Subthemes & Units of meaning \\
\hline Sexual freedom & $\begin{array}{l}\text { Sought after promiscuity and } \\
\text { sexual experimentation }\end{array}$ & $\begin{array}{l}\text { The woman experimenting with various } \\
\text { men before choosing one } \\
\text { Absence of taboos } \\
\text { A women who has been with more men is } \\
\text { well-regarded }\end{array}$ \\
\cline { 2 - 4 } & Social and sexual empowerment & $\begin{array}{l}\text { Women take the initiative } \\
\text { The woman proposes sex to the man } \\
\text { The woman is in charge in the sexual } \\
\text { relationship } \\
\text { A woman from a powerful family can make } \\
\text { the decisions }\end{array}$ \\
\hline $\begin{array}{l}\text { Maternity and } \\
\text { control of one's body }\end{array}$ & $\begin{array}{l}\text { Interest in contraceptive } \\
\text { methods }\end{array}$ & $\begin{array}{l}\text { Contraceptives are seen as necessary } \\
\text { Long-acting contraceptives are favored } \\
\text { They are interested in protecting themselves } \\
\text { from pregnancy }\end{array}$ \\
\cline { 2 - 4 } & Maternity linked to marriage & $\begin{array}{l}\text { An unwanted child is one which does not } \\
\text { have a father } \\
\text { Having a child without a father is a source } \\
\text { of stigma } \\
\text { An unwanted child is abandoned, given up } \\
\text { for adoption, killed or left to die } \\
\text { Hidden abortion }\end{array}$ \\
\hline \multirow{2}{*}{$\begin{array}{l}\text { Sustaining } \\
\text { behaviors }\end{array}$} & Cultural determinants & $\begin{array}{l}\text { Lack of planning or preventative culture. } \\
\text { Avoiding/Delaying attending health centers } \\
\text { Use of traditional medicine } \\
\text { Pregnancy does not stop sex work. }\end{array}$ \\
\cline { 2 - 3 } & Social determinants & $\begin{array}{l}\text { Social invisibility } \\
\text { Drug addiction } \\
\text { Lack of knowledge/interest regarding sexual } \\
\text { and reproductive health rights }\end{array}$ \\
\hline
\end{tabular}

